\title{
QuEChERS and $C_{18}$ as solid phase extraction sorbent - ultra- high performance liquid chromatography -ultraviolet-visible method for determination of nine parabens in cosmetics products
}

\author{
Minh-Duc Thi Nguyen, Kim-Ngan Huynh Nguyen, Ngoc-Van Thi Nguyen*
}

Can Tho University of Medicine and Pharmacy, Viet Nam; 179 Nguyen Van Cu street, Ninh Kieu District, Can Tho city, Viet Nam.

\begin{tabular}{|c|c|}
\hline Info Article & ABSTRACT \\
\hline $\begin{array}{l}\text { Submitted: } 02-03-2020 \\
\text { Revised: } 20-07-2020 \\
\text { Accepted: } 28-07-2020\end{array}$ & $\begin{array}{l}\text { Concerns are growing about human exposure to endocrine-disrupting } \\
\text { chemicals (EDCs), especially during the preadolescent development stage. } \\
\text { Parabens are prevalent EDCs widely used as additives in cosmetics. So, the } \\
\text { determination of parabens in such products is important. In this study, we } \\
\text { developed a reliable and sensitive method to determine simultaneously nine } \\
\text { common parabens (methylparaben, ethylparaben, phenylparaben, } \\
\text { benzylparaben, penthylparaben, and two groups of isomeric compounds } \\
\text { include propylparaben, isopropyl paraben, and butylparaben, } \\
\text { isobutylparaben) in cosmetics products. The QuEChERS and solid-phase } \\
\text { extraction techniques are used for extraction parabens from non-surfactant } \\
\text { cosmetics (perfume, mouth wash solution) and surfactant cosmetics } \\
\text { (shampoo, cream, gel), respectively and quantified by using ultra- } \\
\text { performance liquid chromatography coupled with the ultraviolet-visible } \\
\text { detector. All nine compounds showed good linearity with regression } \\
\text { coefficients predominantly above } 0.990 \text {. The LOD and LOQ of parabens were } \\
0.07 \mu \text { /mL; } 0.2 \mu \mathrm{m} \text { /mL, respectively. The recoveries ranged from } 80 \text { to } 110 \% \\
\text { with the relative standard deviations below } 8 \% \text {. The developed method was } \\
\text { successfully applied to determine parabens in various commercial cosmetic } \\
\text { products from a local supermarket and the total parabens concentrations are } \\
\text { in a wide-ranged from } 2.0 \text { to } 1270 \text { mg/kg. } \\
\text { Kevwords: narahen }\end{array}$ \\
\hline
\end{tabular}

\section{INTRODUCTION}

Cosmetics are commercially available products that can protect human skin from ultraviolet (UV) radiation and improve skin appearance because of their anti-oxygenation effects. Cosmetics products are used daily by many consumers, contributing to the improvement of their well-being (Guan et al., 2005). Parabens or esters of 4-hydroxybenzoic acid with slight differences in the ester group, including methylparaben (MeP), ethylparaben (EtP), phenylparaben (PhP), benzylparaben (BzP), pentylparaben (PeP), propylparaben (PrP) and isopropylparaben (i-PrP); butylparaben (BuP) and isobutylparaben (i-BuP) are the most commonly used preservatives in cosmetic products to inhibit or prevent microbial and fungal growth and extend the shelf life of the products, because of the broad antimicrobial spectrum, good stability, nonvolatility, and effectivity in a wide $\mathrm{pH}$ range (Soni et al., 2005). However, some studies have shown that the big amount using these preservatives in cosmetics may result in potential health risks due to their estrogenic activity and perturbation of the endocrine system (Márquez-Sillero et al., 2010). Human exposure to parabens can occur through different pathways, such as ingestion, inhalation, and dermal exposure (Larsson et al., 2014). However, regulations have only accounted for their use in the formulation of cosmetic products, whose maximum concentration is $0.4 \%$ for individual use and $0.8 \%$ for use in mixtures, except 
propylparaben and butylparaben, whose limits decrease to 0.14 and $0.19 \%$, respectively (European Commission, 2014).

With regard to the analytical techniques for the determination of preservatives, reported methods for the determination of parabens are based on gas chromatography (GC) (Lin et al., 2000), capillary electrophoresis (CE) (Wang et al., 1998) and high-performance liquid chromatography (HPLC) (Borremans et al., 2004). Among those methods, reversed-phase liquid chromatography (LC) coupled with ultravioletvisible spectrophotometry (UV/Vis) (Kim et al., 2011; Piao et al., 2014), and tandem mass spectrometry (MS/MS) (Moreta et al., 2015) detectors are the most commonly used. Among them, liquid chromatography (LC) has been the most common.

About sample preparation, different extraction procedures are developed. Given the complexity of cosmetic matrices and low concentrations at which parabens are found, a step of sample preparation is needed to preconcentrate, decrease interferences, and provide cleaner extract for further analysis (Piao et al., 2014). In the vast majority of cases, liquid-liquid extraction (IlE) has been the primary sample preparation method to achieve this objective but IlE methods are time consuming and tedious, and utilize large amounts of high purity organic solvents, which are potentially toxic and expensive. Another extraction method liquid-phase micro extraction (IPME) which is simple to implement and generally fast, however, the technique is not suitable for complex samples. While solid phase extraction (SPE) is one of the most common methods of extraction of contaminants from samples because of its effectiveness (MárquezSillero et al., 2010). SPE has been widely reported for the extraction of parabens (Renz et al., 2013) coupled with other sample preparation techniques (Rocío-Bautista et al., 2015).

For non-surfactant cosmetics, QuEChERS has been less studied than other sample preparation methods that have been applied to the analysis of parabens in hair spray, perfume, deodorant, and mouthwash. QuEChERS extraction method was originally developed for the multiresidue analysis of pesticides in food (DeArmond et al., 2015). Nowadays, it is a sample preparation technique of choice for the analysis of a variety of chemicals in a variety of different samples. (Perestrelo et al., 2015). Analyses of parabens are important because many recent studies have observed that exposure to parabens may either modulate or disrupt the endocrine system, exhibit estrogenic activity, lead to cancer, and cause adverse effects.

To the best of our knowledge, this is the first work addressing a reliable and useful analytical method, special emphasis is paid concerning rapidness and simplicity on sample preparation, besides on accuracy and sensitivity. To reach this purpose, methods base on SPE and QuEChERS with determination by ultra-liquid chromatography coupled with ultraviolet-visible detector are validated. Thus, the aim of this study is simultaneous determination of nine parabens in cosmetics products using SPE and QuEChERS for sample preparation.

\section{MATERIAL AND METHODS Chemical and materials}

HPLC-grade acetonitrile, methanol, and water were purchased from Merck Company (Darmstadt, Germany). Methylparaben 99.9\% (MeP), ethylparaben 99.8\% (EtP), phenylparaben 99.0\% (PhP), benzylparaben (BzP) 99.2\%, pentylparaben $99.7 \%$ (PeP), propylparaben $99.8 \%$ (PrP) and isopropylparaben 99.7\% (i-PrP); butylparaben $99.7 \%$ (BuP) and isobutylparaben 99.7\% (i-BuP) standards were supplied from Sigma-Aldrich (Milwaukee, WI, USA). The solid phase extraction column was Silicycle $\mathrm{C}_{18}$ $500 \mathrm{mg} / 6 \mathrm{~mL}$ (Quebec, Canada).

\section{Instrumentation and chromatographic conditions}

The chromatographic analysis was performed on the Waters UPLC Acquity H-class system equipped with a tunable UV-Visible detector (TUV). Chromatographic data were acquired and processed by Masslynx 4.0 software. The analytical column was a UPLC Cortecs $\mathrm{C}_{18}$ plus $(2.1 \times 100 \mathrm{~mm}, 1.6 \mu \mathrm{m})$. Elution programs were studied by using acetonitrile as eluent (A) and water as eluent (B). The optimized gradient elution program was as follows: $0.0-2.0 \mathrm{~min}, 28 \% \mathrm{~A} ; 2$ $8.5 \mathrm{~min}$, linear gradient $40 \% \mathrm{~A} ; 8.5-9.0 \mathrm{~min}$, linear gradient $45 \% \mathrm{~A} ; 9.0-10.7 \mathrm{~min}$, linear gradient 90\% A; 10.7-13min, linear gradient $100 \% \mathrm{~A}$; 13-13.5min, linear gradient $28 \% \mathrm{~A} ; 13.5-15.0 \mathrm{~min}$, hold 28\% A. All chromatographic experiments were performed at room temperature. The injection volume was $10.0 \mu \mathrm{L}$. The separation was accomplished at a constant flow of $0.2 \mathrm{~mL} / \mathrm{min}$. The detection wavelength was $260 \mathrm{~nm}$ for identifying all parabens. 


\section{Data analysis}

Masslynx software (Waters) was used for instrument control and data processing. Data analysis for validation was performed by using Excel software version 2010 (Microsoft).

\section{Preparation of standard solutions}

Individual standard stock solutions were prepared at a concentration of $400 \mu \mathrm{g} / \mathrm{mL}$ in methanol and stabled for about 6 months when stored in a refrigerator at $4{ }^{\circ} \mathrm{C}$. The working standard solution containing $40 \mu \mathrm{g} / \mathrm{mL}$ of each standard compound were prepared daily by mixing and diluting the stock standard solution with methanol to the required concentrations.

\section{Sample preparation}

In our study, we used the QuEChERS method for analysis of parabens in non-surfactant cosmetics (perfume, mouthwash solution) and solid phase extraction-SPE method for surfactant cosmetics (cream, gel, shampoo). QuEChERS and SPE procedure were described below:

\section{QuEChERS procedure}

QuEChERS method was a sample preparation approach developed by Anastassiades, et al. as a simple, rapid, effective, yet inexpensive way to extract analytes from the matrix, followed by a dispersive solid-phase extraction (d-SPE) cleanup of the extract (Perestrelo et al., 2015). One gram of cosmetics was weighed into a $50 \mathrm{~mL}$ centrifuge tube, then added $5 \mathrm{~mL}$ of water to disperse sample, then $10 \mathrm{~mL}$ of acetonitrile was added and shake vigorously for $2 \mathrm{~min}, 6 \mathrm{~g}$ anhydrous $\mathrm{Na}_{2} \mathrm{SO}_{4}$ and $1.5 \mathrm{~g} \mathrm{NaCl}$ were then added and the mixture was shaken immediately for one minute. Centrifugation was carried out at $4000 \mathrm{rpm}$ for $5 \mathrm{~min}$ and the clean-up step was done with dSPE included a mixture of $1 \mathrm{~g} \mathrm{MgSO}_{4}, 800 \mathrm{mg}$ PSA and $400 \mathrm{mg} \mathrm{C}_{18}$ with $5 \mathrm{~mL}$ of acetonitrile. The mixture was shaken well and centrifuged at 4000 rpm for $5 \mathrm{~min}$, after that, $4 \mathrm{~mL}$ was taken out, dried using nitrogen evaporator and residue dissolved in $4.0 \mathrm{~mL}$ of methanol, water in a ratio of $(40: 60)$ and filtered through a $0.22 \mu \mathrm{m}$ Nylon filter and transferred into a vial. The final samples were injected on UPLC/TUV.

\section{SPE procedure}

To extract parabens from cosmetics, some previous studies used methanol (Shen et al., 2007), diethyl ether (European Commission, 1996), acetonitrile (Huang et al., 2006), chloroform (Jain et al., 2013). In our study, to minimize the non-polar matrix co-extractives and optimize extraction efficiency, we examined several ratios of methanol, acetonitrile and sample weight.

About $400 \mathrm{mg}$ of cosmetics was accurately weighed into a $50 \mathrm{~mL}$ centrifuge tube then $1 \mathrm{~mL}$ of methanol was added, then vortex for $5 \mathrm{~min}$, after that centrifuged at $4.000 \mathrm{rpm}$ for $1 \mathrm{~min}$. The supernatant was transferred to another $50 \mathrm{~mL}$ centrifuge tube and diluted to $25 \mathrm{~mL}$ by water.

The $\mathrm{C}_{18}$ SPE cartridge was conditioned with $6 \mathrm{~mL}$ of $\mathrm{MeOH}$ and equilibrated with $6 \mathrm{~mL}$ of water. $25 \mathrm{~mL}$ prepared sample solution was loaded on the SPE cartridge at a flow rate of $1 \mathrm{~mL} / \mathrm{min}$, washed with $6 \mathrm{~mL}$ water and $2 \mathrm{~mL}$ mixture of methanol and water in a ratio of 20:80 (v/v) and eluted with $2 \mathrm{~mL}$ mixture of methanol and water in a ratio of $80: 20$ (v/v). The eluted solution was diluted to $4 \mathrm{~mL}$ by water and filtered through a $0.22 \mu \mathrm{m}$ Nylon filter and transferred into a vial.

\section{Method validation}

Method validation is the process used to confirm that the analytical procedure employed for a specific test is suitable for its intended use. The proposed method was validated following the guideline from the Association of Official Analytical Chemists (AOAC, 2002). The testing parameters were system suitability, specificity, linearity, the limit of detection (LOD) and quantification (LOQ), accuracy and precision.

\section{RESULTS AND DISCUSSION \\ Optimization of the UPLC method}

The choice of the optimal chromatographic conditions was performed by the analysis of a multi-standard mixture working solution, containing $1 \mu \mathrm{g} / \mathrm{mL}$ of each standard compound. Two different elution methods (isocratic and gradient) were examined by using reverse-phase Cortecs $\mathrm{C}_{18}$ plus column with detection wavelength at $260 \mathrm{~nm}$.

The result showed that all parabens were completely separated in about $13 \mathrm{~min}$ by using the isocratic program consisting of acetonitrile and water in a ratio of 40:60 (v/v). However, this program could not elute strongly retained interferences from the column resulted in late eluted peak appearing in the next sample chromatogram, which decreased the accuracy, reproducibility of analytes peak area and the performance of the analytical column (Figure 1a). 


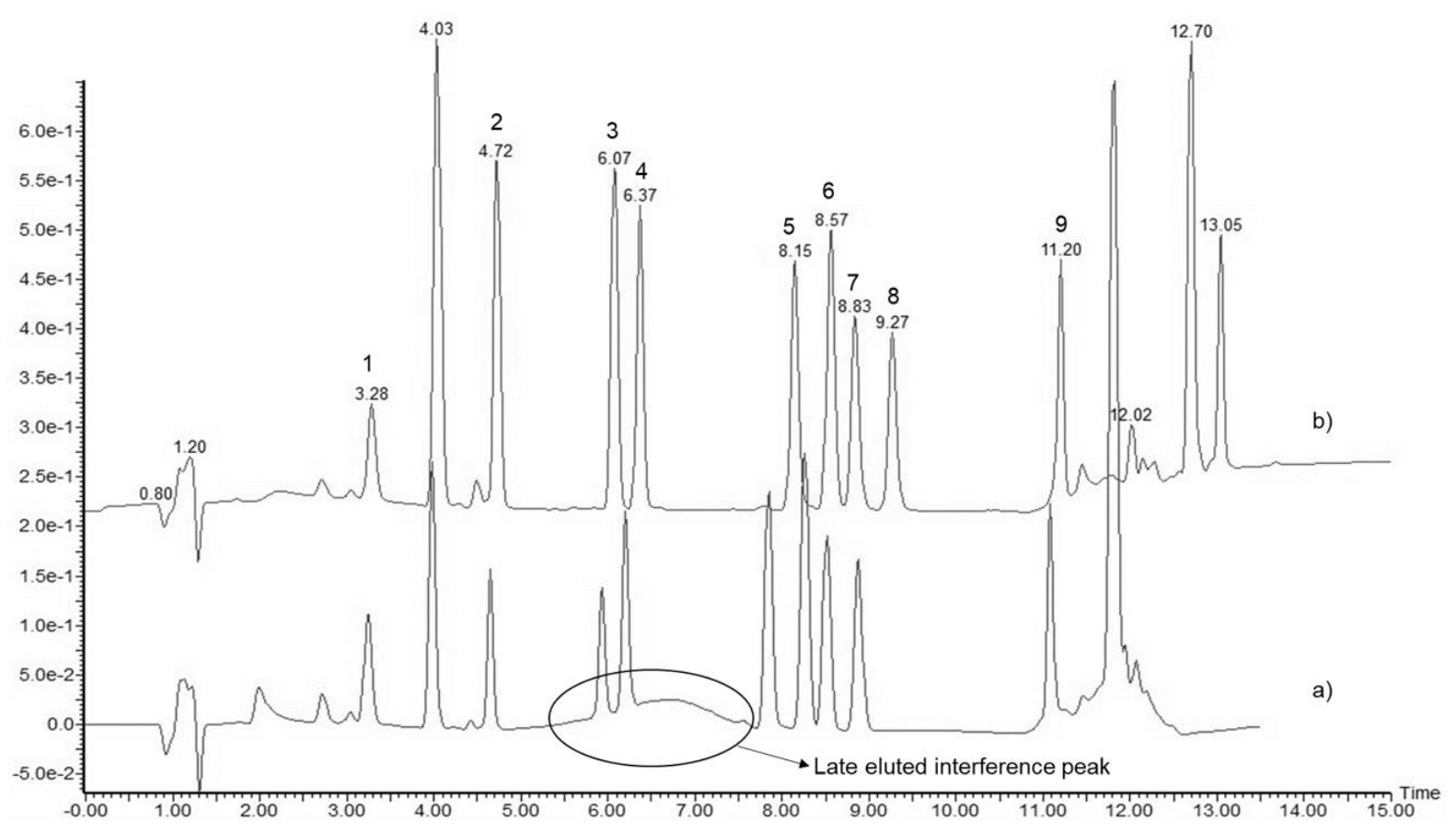

Figure 1. UPLC chromatogram of mixed parabens standard solution at $260 \mathrm{~nm}$. 1.MeP, 2.EtP, 3.i-PrP, 4.PrP, 5.PhP, 6.i-BuP, 7.BuP, 8.BzP, 9.PeP. a) Isocratic elution progam; b) Optimzed gradient elution program

At lower acetonitrile concentration (30\%), the separation was achieved but with long analysis time ( $>30 \mathrm{~min})$. Therefore, the gradient method was applied. Some gradient elution programs were studied. Figure $1 \mathrm{~b}$ showed the chromatogram of optimal gradient elution. With this program, all analytes and matrices were well separated with the total run time of about $15 \mathrm{~min}$.

\section{Optimization of sample preparation}

For analysis of cosmetic products, sample pretreatment plays an important role to remove the sample matrices and eliminate the analytical interference. Preliminary experiments suggested that liquid-liquid extraction was not an effective way to use for the determination of parabens in cosmetics, because of the formation of stable emulsion and wide polarity range of parabens. To solve these issues, QuEChERS and solid-phase extraction (SPE) was evaluated to be applied to the sample pretreatment for parabens.

\section{QuEChERS method}

To evaluate the purification efficiency of each procedure, the dried residues of the tested samples were weighed and compared. First of all, the extraction solvent was the primary consideration, which had a great impact on the efficiency of the extraction. Based on the solubility of parabens, several solvent ratio combinations of water and methanol with acetonitrile were investigated. The results showed that the mixture of water and acetonitrile in a ratio of $1: 2(\mathrm{v} / \mathrm{v})$ had the highest recovery and was similar to the mixture methanol and acetonitrile in the same ratio. Besides, when the ratio of methanol increased, the liquid-liquid portioning and salting-out step were less efficient, resulted in more polar interference in the acetonitrile layer. Therefore, the mixture of water and acetonitrile was more suitable than methanol and acetonitrile.

Due to the complexity of a cosmetic matrix, a cleanup step was necessary for the pretreatment. Basically, PSA (primary secondary amine) and $\mathrm{C}_{18}$ are the most commonly used as adsorbents in the d-SPE cleanup of QuEChERS. PSA is a weak anion exchanger that can remove various organic acids, fatty acids, and some acidic polar interference, and $\mathrm{C}_{18}$ can absorb substances like lipids and other compounds that have long carbon-chain (Perestrelo et al., 2015). Therefore, to remove nonpolar interference such as surfactants, fatty acids, alkyl-betaines, mineral oils, pigments from matrix, we examined four d-SPE kits: kit 1 (200mg $\mathrm{MgSO}_{4}$, 


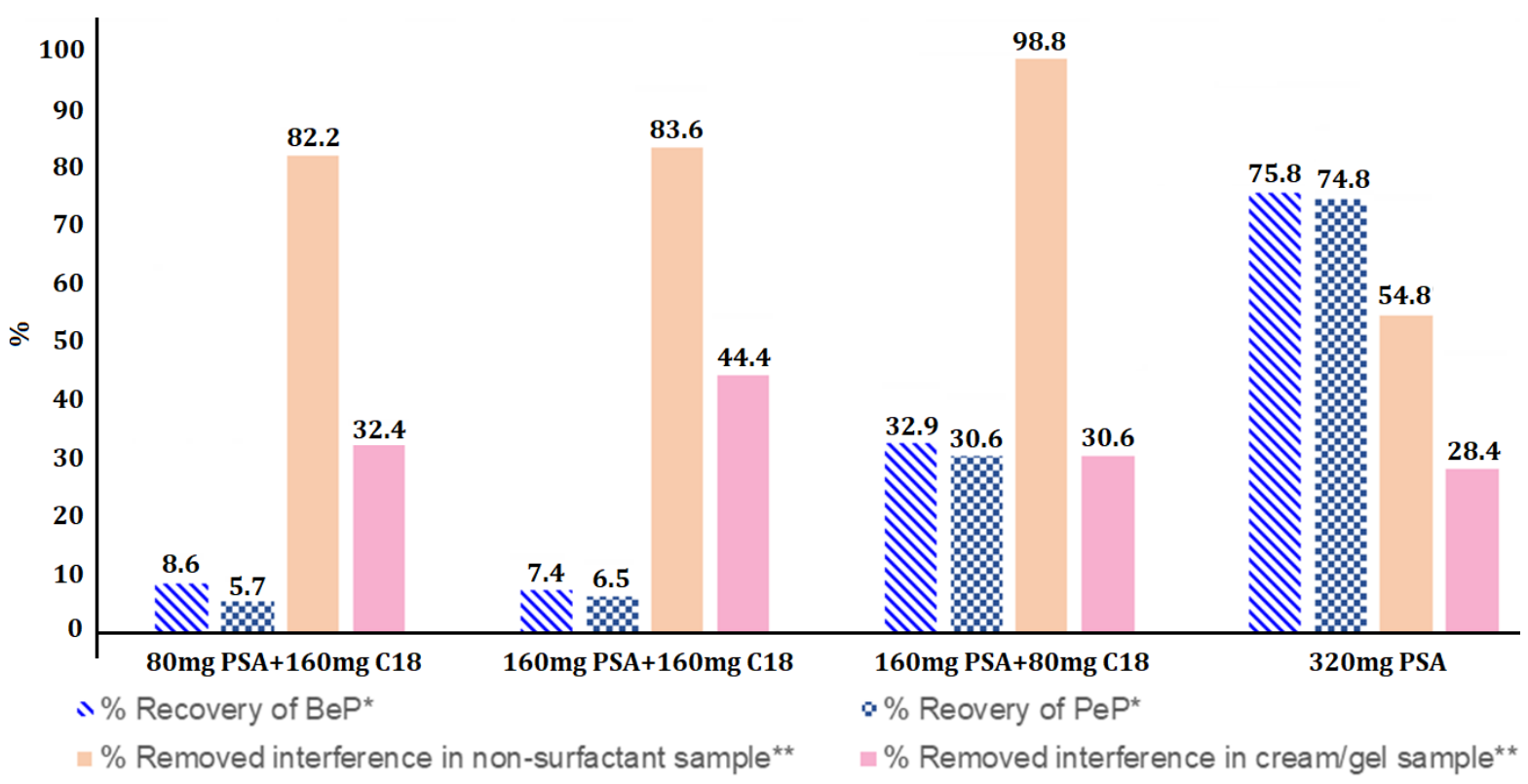

Figure 2. Effect of the amount of PSA and C18 in d-SPE kit on the recovery (\%) of parabens and purification efficiency.

${ }^{*}$ ): Recovery values were calculated by comparison between the peak area of parabens from a tested sample and standard parabens solution at the same concentration; $\left.{ }^{* *}\right)$ : Values were calculated by comparison between the mass of dried residue from a tested sample and which were not applied d-SPE

Table I. Recovery (\%) of parabens and removed interference (\%) in several washing solvents after loading in SPE $\mathrm{C}_{18}$ cartridge

\begin{tabular}{cccc}
\hline Washing solvent & $\begin{array}{c}\text { Recovery of MeP } \\
\mathbf{( \% )}\end{array}$ & $\begin{array}{c}\text { Removed interference } \\
(\mathbf{\%}) *\end{array}$ & $\begin{array}{c}\text { Recovery ranged of nine parabens } \\
(\mathbf{\%}) * *\end{array}$ \\
\hline $10 \% \mathrm{ACN}$ & 97.4 & 6.5 & $90.8-102.6$ \\
$20 \% \mathrm{ACN}$ & 61.6 & 64.8 & $61.6-105.9$ \\
$30 \% \mathrm{ACN}$ & 33.2 & 80.2 & $33.2-94.6$ \\
$10 \% \mathrm{MeOH}$ & 97.5 & 1.3 & $97.5-105.2$ \\
$20 \% \mathrm{MeOH}$ & 94.2 & 54.4 & $94.2-101.3$ \\
$30 \% \mathrm{MeOH}$ & 60.8 & 71.4 & $60.8-97.3$ \\
\hline
\end{tabular}

${ }^{*}$ ): Values were calculated by comparison between the mass of dried residue from a tested sample and which were washed by water; $\left({ }^{* *}\right)$ : Values were calculated by comparison between the peak area of parabens from a tested sample and standard parabens solution at the same concentration

80mg PSA, 160mg C18), kit 2 (200mg $\mathrm{MgSO}_{4}$, $160 \mathrm{mg} P S A, 160 \mathrm{mg} \mathrm{C} 18$ ), kit 3 (200mg $\mathrm{MgSO}_{4}$, $160 \mathrm{mg}$ PSA, 80mg C18), kit 4 (200mg $\mathrm{MgSO}_{4}, 320 \mathrm{mg}$ PSA) per $1 \mathrm{~mL}$ extracted solution. The results showed that all mixtures of PSA and $\mathrm{C}_{18}$ (kit 1, 2, 3) adsorbed more than $80 \%$ interference of nonsurfactant cosmetics, and presented poor purification efficiency with cream and gel samples (Figure 2). The use of kit 1 and 2 resulted in a great decrease (almost 90\%) in the recoveries of $\mathrm{BzP}, \mathrm{PeP}$ while the other compounds had a good recovery. Interestingly, kit 4 which had the highest PSA amount and did not have $\mathrm{C}_{18}$ presented the highest recovery of these compounds $(>70 \%)$, however, it could not remove non-polar interference effectively. Additionally, kit 3 displayed the best results among all four d-SPE kits, it had better recovery of BzP, PeP (>30\%) and presented the highest purification efficiency. The main explanation was that $\mathrm{C}_{18}$ sorbent adsorbed $\mathrm{BzP}, \mathrm{PeP}$ which were the most hydrophobicity parabens resulted in its poor recovery. 


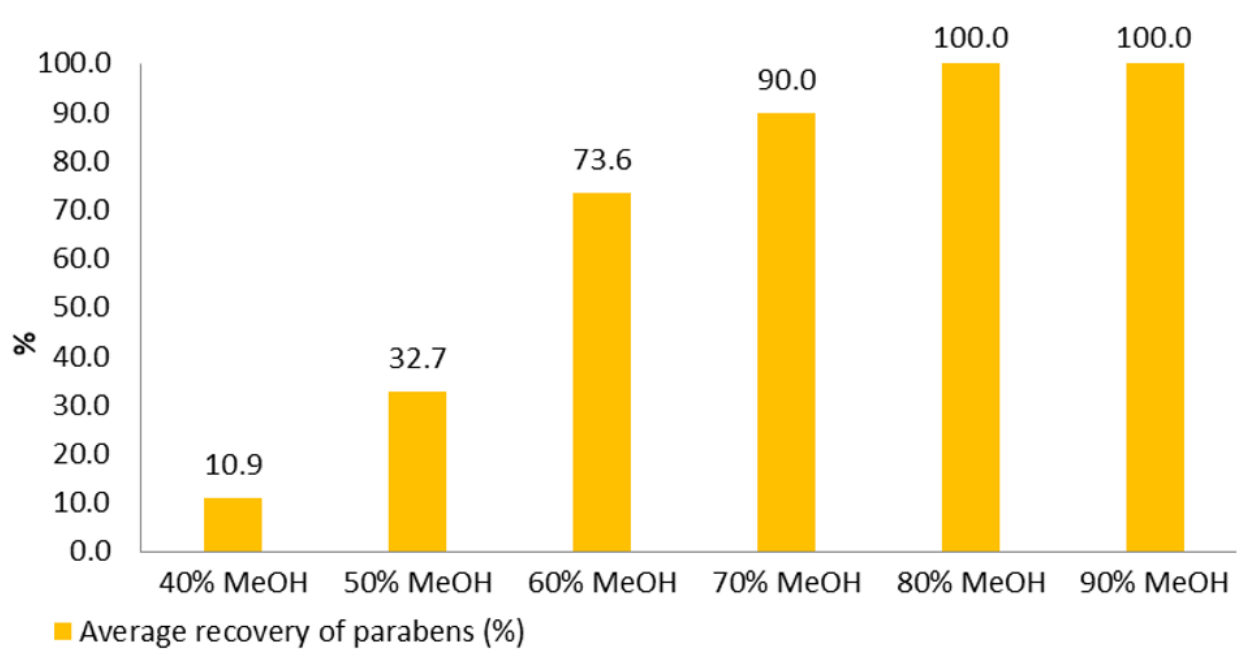

Figure 3. Effect of the methanol (\%) in elution solution on the recovery (\%) of parabens.

Table II. Precision, accuracy data, calibration equations and correlation coefficients of shampoo matrix

\begin{tabular}{|c|c|c|c|c|c|c|c|}
\hline \multirow[b]{2}{*}{ Parabens } & \multicolumn{3}{|c|}{ Recovery (\%) } & \multicolumn{2}{|c|}{ Precision $(1.0 \mu \mathrm{g} / \mathrm{g})(\mathrm{n}=6)$} & \multicolumn{2}{|c|}{ Calibration curve } \\
\hline & $\begin{array}{l}\text { Low-level } \\
(0.8 \mu \mathrm{g} / \mathrm{g})\end{array}$ & $\begin{array}{l}\text { Mid-level } \\
(1.0 \mu \mathrm{g} / \mathrm{g})\end{array}$ & $\begin{array}{c}\text { High-level } \\
(1.2 \mu \mathrm{g} / \mathrm{g})\end{array}$ & $\begin{array}{c}\text { Intraday RSD } \\
(\%)\end{array}$ & $\begin{array}{l}\text { Interday } \\
\text { RSD (\%) }\end{array}$ & Equation & $\mathbf{r}^{2}$ \\
\hline $\mathrm{MeP}$ & 101.0 & 108.1 & 101.3 & 6.5 & 7.2 & $y=11253 x$ & 0.999 \\
\hline EtP & 95.2 & 98.0 & 95.5 & 6.2 & 3.3 & $y=32846 x$ & 0.998 \\
\hline i-PrP & 92.1 & 95.8 & 99.6 & 1.0 & 4.0 & $y=15788 x$ & 0.998 \\
\hline PrP & 90.7 & 94.4 & 98.4 & 5.2 & 4.9 & $y=14882 x$ & 0.998 \\
\hline $\mathrm{PhP}$ & 94.0 & 95.6 & 99.1 & 1.9 & 1.4 & $y=28693 x$ & 0.997 \\
\hline i-BuP & 92.8 & 95.0 & 94.2 & 4.9 & 6.0 & $y=32388 x$ & 0.996 \\
\hline $\mathrm{BuP}$ & 90.4 & 95.0 & 99.6 & 5.2 & 4.3 & $y=22246 x$ & 0.997 \\
\hline $\mathrm{BzP}$ & 87.8 & 98.0 & 98.4 & 4.8 & 5.7 & $y=22074 x$ & 0.997 \\
\hline $\mathrm{PeP}$ & 104.2 & 101.2 & 98.5 & 2.4 & 2.3 & $y=19262 x+834$ & 0.999 \\
\hline
\end{tabular}

The results indicated that PSA adsorbed interference from cosmetics more effective than $\mathrm{C}_{18}$, and the PSA/C 18 combination could improve the clean-up performance of the d-SPE kit. Therefore, we suggested a QuEChERS method with a d-SPE kit combined 200mg $\mathrm{MgSO}_{4}, 160 \mathrm{mg}$ PSA and $80 \mathrm{mg} \mathrm{C}_{18}$ per $1 \mathrm{~mL}$ extracted solution for determination parabens (excepted $\mathrm{BzP}, \mathrm{PeP}$ ) in non-surfactant cosmetic.

\section{Solid-phase extraction}

The results showed that a similar recovery of parabens with methanol and acetonitrile as extraction solvent at sample weight, solvent volume in a ratio of $1: 4(\mathrm{w} / \mathrm{v})$. Due to acetonitrile precipitated hydrophobic excipients less effective than methanol and decreased the retention efficient of MeP in SPE C18, we suggested methanol as an extraction solvent.
To eliminate the influence of the matrix by an effective clean-up procedure, the SPE $\mathrm{C}_{18}$ cartridge $(500 \mathrm{mg}, 6 \mathrm{~mL}$ ) was used. Different washing and eluting solvents were examined to optimize clean-up efficiency. Methanol extracts of the samples spiked with parabens were diluted by water to $25 \mathrm{~mL}$ and loaded onto the SPE columns. Data from table I showed that the recovery of MeP was most affected by the ratio of organic solvent, especially acetonitrile because MeP was more polar than other parabens. Besides, when samples were washed with $20 \%$ of aqueous methanol, all parabens presented a good recovery ( $>90 \%$ ) and samples were purified acceptably. Therefore, $20 \%$ of methanol in water was preferred in this study. Several ratios of methanol in water (40-90\%) were examined to find out suitable elution solvent which strong enough to elute all analytes weak enough to leave and strongly retained impurities behind. 
Table III. Results of parabens in cosmetic products

\begin{tabular}{|c|c|c|c|c|c|c|c|c|c|c|c|}
\hline \multirow{2}{*}{ Matrix } & \multirow{2}{*}{ Sample } & \multicolumn{10}{|c|}{ Concentrations of parabens (\%) } \\
\hline & & MeP & EtP & i-PrP* & PrP & PhP* & i-BuP* & BuP & BzP* & PeP* & Total \\
\hline \multirow{12}{*}{ Shampoo } & SH01 & 0.0012 & -- & -- & -- & -- & -- & -- & -- & -- & 0.0012 \\
\hline & SH02 & 0.0005 & -- & -- & -- & -- & -- & 0.0002 & -- & -- & 0.0007 \\
\hline & $\mathrm{SH} 03$ & 0.0014 & 0.0019 & -- & 0.0002 & -- & -- & -- & -- & -- & 0.0035 \\
\hline & SH04 & 0.0864 & -- & -- & 0.0197 & -- & -- & -- & -- & 0.0091 & 0.1152 \\
\hline & SH05 & -- & -- & -- & 0.0006 & -- & -- & -- & 0.0005 & -- & 0.0011 \\
\hline & SH06 & -- & -- & -- & 0.0005 & -- & -- & -- & -- & -- & 0.0005 \\
\hline & SH07 & -- & -- & -- & 0.0006 & -- & -- & -- & -- & -- & 0.0006 \\
\hline & SH08 & -- & -- & -- & 0.0005 & -- & -- & -- & -- & -- & 0.0005 \\
\hline & SH09 & 0.0005 & -- & -- & -- & -- & -- & -- & -- & -- & 0.0005 \\
\hline & SH10 & 0.0006 & -- & -- & 0.0007 & -- & -- & -- & -- & -- & 0.0013 \\
\hline & SH11 & -- & -- & -- & -- & -- & -- & -- & -- & -- & -- \\
\hline & SH12 & 0.0027 & -- & -- & 0.0001 & -- & -- & -- & -- & -- & 0.0028 \\
\hline \multirow{4}{*}{ Shower gel } & GE01 & -- & -- & -- & -- & -- & -- & -- & -- & -- & -- \\
\hline & GE02 & 0.0011 & -- & -- & -- & -- & -- & -- & -- & -- & 0.0011 \\
\hline & GE03 & -- & -- & -- & -- & -- & -- & -- & -- & -- & -- \\
\hline & GE04 & 0.0016 & -- & -- & -- & -- & -- & -- & -- & -- & 0.0016 \\
\hline \multirow{3}{*}{$\begin{array}{l}\text { Feminine } \\
\text { wash }\end{array}$} & FW01 & -- & -- & -- & -- & -- & -- & 0.0091 & -- & -- & 0.0091 \\
\hline & FW02 & -- & -- & -- & -- & -- & -- & 0.0006 & -- & -- & 0.0006 \\
\hline & FW03 & 0.0102 & -- & -- & 0.0673 & -- & -- & 0.039 & -- & -- & 0.1165 \\
\hline \multirow{2}{*}{$\begin{array}{l}\text { Makeup } \\
\text { remover }\end{array}$} & MR01 & 0.127 & -- & -- & -- & -- & -- & -- & -- & -- & 0.127 \\
\hline & MR02 & -- & -- & -- & -- & -- & -- & -- & -- & -- & -- \\
\hline Hand wash & HW01 & -- & -- & -- & -- & -- & -- & 0.0013 & -- & -- & 0.0013 \\
\hline Cleanser & CL01 & 0.001 & -- & -- & -- & -- & -- & -- & -- & -- & 0.001 \\
\hline
\end{tabular}

$(--)$ : Not detected; $\left(^{*}\right)$ : Parabens were prohibited in cosmetic products by European Commission (European Commission, 2014).

The resulted showed that $80 \%$ of methanol provided the optimum recovery of all parabens (Figure 3).

\section{Matrix effect evaluation}

After optimizing SPE parameters and QuEChERS method, the matrix effect was evaluated by comparison of the data from aqueous samples and blank samples cream, shampoo, non-surfactant cosmetics (perfume and mouthwash solution) both spiked with the standard parabens solutions at $2 \mu \mathrm{g} / \mathrm{mL}$. The results showed that the presence of polar and non-polar interferences did not interfere in the identification and quantification parabens in cosmetic products.

\section{Method validation}

System suitability was tested by performing six replicate injections and determining the repeatability of retention time and peak area of parabens. The \%RSD values of peak area and retention time of all parabens ranged from 0.09 to 1.65 , and 0.06 to 0.92 , respectively. So, the proposed method met the requirement (RSD\% $\leq$ $2 \%)$.

The linear correlation coefficients $\left(r^{2}\right)$ are higher than 0.990 wich was the acceptance value of AOAC guideline with the range from 0.2 to $2.0 \mu \mathrm{g} / \mathrm{mL}$ (Table II). The LOD and LOQ values calculated by considering a value 3 times and 10 times that of the baseline noise were 0.07 and 0.2 
$\mu \mathrm{g} / \mathrm{mL}$, respectively which allowed the determination of the target compound in a wide range of concentrations. The LODs of the parabens obtained in this study are slightly better than those reported in other studies using HPLC/UV instruments (Fei et al., 2011; Gao and LegidoQuigley, 2011; Zotou et al., 2010).

The recovery and precision data were obtained for all parabens spiked at concentrations of $0.8,1.0$ and $1.2 \mu \mathrm{g} / \mathrm{mL}$ in shampoo and each concentration was conducted on six replicates. The results are summarized (Table II). The overall intra- and inter-day variations (RSDs) of nine parabens were less than $6.5 \%$ and $7.2 \%$, respectively, with the recovery ranged within $87.8-$ $106.6 \%$ and met the requirement of AOAC guideline (75-120\%). The developed method resulted in satisfactory recoveries for all the tested compounds.

\section{Application to real samples}

To evaluate the method applicability, the proposed method was applied to determine parabens in 23 cosmetic products including shampoo, shower gel, feminine wash, makeup remover, hand wash, and cleanser collected from the supermarket (Table III). The results showed that the detection frequencies of parabens in these samples $(n=23)$ were 19 samples $(82.6 \%)$, which contained at least one paraben. In general, MeP and PrP were the most commonly used parabens since their combination produces a synergic effect against various microorganisms, which was similar to the results of previous studies (Lokhanauth and Snow, 2016; Moreta et al., 2015). In these samples, the parabens were quantified in a wide-ranged from 0.0002 to $0.1270 \%$ (2 - $1270 \mathrm{mg} / \mathrm{kg}$ ). Total concentrations of parabens in all samples were below $0.14 \%$, which was within the recommendations of the European Commission for cosmetic products (European Commission, 2014). Besides, three prohibited parabens combined i$\mathrm{PrP}, \mathrm{PhP}$, and i-BuP were not detected in all cosmetic samples. However, two shampoo samples SH04 and SH05 contained two banned parabens included $\mathrm{PeP}, \mathrm{BzP}$ at 0.0091 and $0.0005 \%$ respectively. The results indicated that the developed method could apply to determine parabens in a wide concentration range and detect banned parabens in various cosmetic products.

\section{CONCLUSION}

A simple and reliable method was developed and validated for the simultaneous determination of parabens from cosmetics. Analytes were extracted and purified by using cost-effective techniques, especially QuEChERS, which was the most popular and flexible sample preparation method in the modern analytical laboratory. Following extraction, the analysis was carried out by ultra-performance liquid chromatography coupled with UV detection, which exhibited good linearity $\left(r^{2}>0.990\right)$. Besides, this instrument provided short analysis time and high sensitive procedure that was important factors for the determination of both permitted and banned parabens in routine analysis.

\section{ACKNOWLEDGEMENTS}

The authors thank the Can Tho University of Medicine and Pharmacy for the use of analytical instruments. We also thank all of our colleagues for their excellent assistance.

\section{REFERENCES}

Anastassiades, M., Lehotay, S.J., Stajnbaher, D., Schenck, F.J., 2003. Fast and easy multiresidue method employing acetonitrile extraction/partitioning and "dispersive solid-phase extraction" for the determination of pesticide residues in produce. J. AOAC Int. 86: 412-431.

Association of Official Analytical Chemists. 2002. Guidelines for for Single Laboratory Validation of Chemical Methods for Dietary Supplements and Botanicals: 17-22.

Borremans M., Van Loco J., Roos P., Goeyens L., 2004. Validation of HPLC Analysis of 2Phenoxyethanol, 1-Phenoxypropan-2-ol, Methyl, Ethyl, Propyl, Butyl and Benzyl 4Hydroxybenzoate (Parabens) in Cosmetic Products, with Emphasis on Decision Limit and Detection Capability. Chromatographia. 59: 47-53.

DeArmond PD., Brittain MK., Platoff GE Jr., Yeung DT., 2015. QuEChERS-based approach toward the analysis of two insecticides, methomyl and aldicarb, in blood and brain tissue. Anal. Meth. 7: 321-328.

European Commission, 1996. Seventh Commission Directive 96/45/EC of 2 July 1996 relating to methods of analysis necessary for checking the composition of cosmetic products. Retrieved October 14, 2019, from: https://publications.europa.eu/en/publicat ion-detail//publication/db4c4a8f-327245ff-b39e-41f6e0fa454d.

European Commission, 2014. Commission regulation (EU) no $1004 / 2014$ of 18 September 2014 Amending Annexes V to 
regulation (EC) No 1223/2009 of the European Parliament and of the council on cosmetic products (Parabens).

Fei T., Li H., Ding M., Ito M., Lin JM., 2011. Determination of parabens in cosmetic products by solid-phase microextraction of poly (ethylene glycol) diacrylate thin film on fibers and ultra-high-speed liquid chromatography with diode array detector. J. Sep. Sci. 34: 1599-1606.

Gao W., Legido-Quigley C., 2011. Fast and sensitive high performance liquid chromatography analysis of cosmetic creams for hydroquinone, phenol and six preservatives. J. Chromatogr. A. 1218: 4307-4311.

Guan Y., Chu Q., Fu L., Ye J., 2005. Determination of antioxidants in cosmetics by micellar electrokinetic capillary chromatography with electrochemical detection. J. Chromatogr. A. 1074: 201-204.

Huang HY., Huang IY., Lin HY., 2006. Separation of parabens in capillary electrochromatography using poly (styrenedivinylbenzene-methacrylic acid) monolithic column. J. Sep. Sci. 29: 20382048.

Jain R., Mudiam MK., Chauhan A., Ch R., Murthy RC., Khan HA., 2013. Simultaneous derivatisation and preconcentration of parabens in food and other matrices by isobutyl chloroformate and dispersive liquid-liquid microextraction followed by gas chromatographic analysis. Food. Chem. 141: 436-443.

Kim K., Mueller J., Park YB., Jung HR., Kang SH., Yoon MH., Lee JB., 2011. Simultaneous determination of nine UV filters and four preservatives in suncare products by highperformance liquid chromatography. J. Chromatogr. Sci. 49: 554 - 559.

Larsson K., Ljung Björklund K., Palm B., Wennberg M., Kaj L., Lindh CH., Jönsson BA., Berglund M., 2014. Exposure determinants of phthalates, parabens, bisphenol a and triclosan in Swedish mothers and their children. Environ. Int. 73: 323-333.

Lin H.S., Wang M.L., Chen C.W., Hwang B.S., Lee M.H., Choong Y. M., 2000. A Gas Chromatographic Method for Determination of Nicotinamide, Paraben Esters and Caffeine in Commercial Health Drinks, Tonic Drinks and Cold Formulas. Journal of Food and Drug Analysis. 8: 180-186.

Lokhnauth JK., Snow NH., 2006. Determination of parabens in pharmaceutical formulations by solid-phase microextraction-ion mobility spectrometry. Anal. Chem. 77: 5938-5946.

Márquez-Sillero I., Aguilera-Herrador E., Cárdenas S., Valcárcel M., 2010. Determination of parabens in cosmetic products using multiwalled carbon nanotubes as solid phase extraction sorbent and corona-charged aerosol detection system. J. Chromatogr. A. 1217: 1-6.

Moreta C., Tena MT., Kannan K., 2015. Analytical method for the determination and a survey of parabens and their derivatives in pharmaceuticals. Environ. Res. 142: 452460.

Perestrelo R., Silva P., Porto-Figueira P., Pereira JAM., Silva C., Medina S., Câmara JS., 2015. A review of recent developments and trends in the QuEChERS sample preparation approach. Open. Chem. 13: 980-1010.

Piao C., Chen L., Wang Y., 2014. A review of the extraction and chromatographic determination methods for the analysis of parabens. J. Chromatogr. B. 969: 139-148.

Renz L., Volz C., Michanowicz D., Ferrar K., Christian C., Lenzner D., El-Hefnawy T., 2013. A study of parabens and bisphenol a in surface water and fish brain tissue from the greater Pittsburgh area. Ecotoxicology. 22: 632-641.

Rocío-Bautista P., Martínez-Benito C., Pino V., Pasán J., Ayala JH., Ruiz-Pérez C., Afonso AM., 2015. The metal-organic framework HKUST-1 as efficient sorbent in a vortex-assisted dispersive micro solid-phase extraction of parabens from environmental waters, cosmetic creams, and human urine. Talanta. 139:13-20.

Shen HY., Jiang HL., Mao HL., Pan G., Zhou L., Cao YF., 2007. Simultaneous determination of seven phthalates and four parabens in cosmetic products using HPLC-DAD and GC-MS methods. J. Sep. Sci., 30: 48 - 54 .

Soni M.G., Carabin I.G., Burdock G.A., 2005. Safety assessment of esters of p-hydroxybenzoic acid (parabens). Food. Chem. Toxicol. 43: 985-1015.

Wang S.P., Chang C.L., 1998. Determination of parabens in cosmetic products by supercritical fluid extraction and capillary zone electrophoresis. Analytica Chimica Acta. 377: 85-93.

Zotou A., Sakla I., Tzanavaras PD., (2010). LCdetermination of five paraben preservatives in saliva and toothpaste samples using UV detection and a short monolithic column, J. Pharm. Biomed. Anal. 53: 785-789. 